Www.jmscr.igmpublication.org

Index Copernicus Value: 79.54

ISSN (e)-2347-176x ISSN (p) 2455-0450

crossrefDOI: https://dx.doi.org/10.18535/jmscr/v7i1.178

\title{
Evaluation of Hormone receptor status in patients with operable breast cancer: a retrospective study at a Regional Cancer Centre in Northeast India
}

\author{
Authors \\ Dr T Dhaneshor Sharma, Dr Neeta Sinam*, Dr Arindam Bhaumik \\ Dr AK Sunita Devi, Dr Sushma Khuraijam, Dr Purnima Rani ghosh \\ Regional Cancer Centre (RCC), Department of Radiotherapy, Regional Institute of Medical Sciences \\ (RIMS), Lamphel, Imphal West- 795001, Manipur \\ *Corresponding Author \\ Dr Neeta Sinam \\ Address- Rajprinee Sangai, Chingmeirong, Imphal East-795010, Manipur, India \\ Phone no.-8729877666, 7005705311, Email: neetasinam828@gmail.com
}

\begin{abstract}
Background: In India, Breast cancer is the most common cancer in female and hormone receptor status is an important prognostic and therapeutic tool in the management of breast cancer. So this study was done with the aim to evaluate the hormone receptor status in patients with operable breast cancer at a Regional Cancer Centre in Northeast India.

Methodology: This study is a retrospective case series study on 180 cases of operable breast cancer who were registered at Regional Cancer Centre, Regional Institute of Medical Sciences (RIMS), Manipur State after histopathological confirmation during the period from September 2015 to August 2018 and patients were reviewed for age, tumour size and metastatic lymph nodes positivity, histopathology, grading, hormone receptor status, staging and menstrual status.

Results: Overall 180 patients was studied and evaluated for hormone receptor status. 90 cases (50.0\%) were both $E R-/ P R-, 66$ cases (36.7\%) were both $E R+/ P R+, 14$ cases $(7.8 \%)$ were $E R+$ and 10 other cases (5.5\%) were only $P R+$. The mean age of presentation was $52.6 \pm 0.82$ yrs and the number of patients reaches a peak between 31 - 50 years (59.4\%). Maximum patients were found to be in poor socio-economic class. Invasive duct carcinoma (96.1\%) was predominant histology. Majority of the cases (84.5\%) had grade-III tumour. $17.8 \%$ of total patients presented in stage-I, $42.8 \%$ in stage-II and $39.4 \%$ in stage-III.

Conclusion: In Northeast India, incidence rate of breast cancer among younger age group has been increasing and more patients were ER/PR negative. Maximum numbers of grade-III tumour were found to be ER/PR negative and as the tumour size increased, ER/PR negativity also increased.

Keyword: Breast cancer, Hormone receptor, Northeast India.
\end{abstract}

\section{Introduction}

In more developed regions, breast cancer is the second cause of cancer death after lung cancer ${ }^{1}$ but it is the most frequent cause of cancer death in less developed region. Even though, incidence rate of breast cancer in India is much lower compared 
with western countries $^{2}$ it is now the most common cancer in women and recently overtaken cervical cancer. ${ }^{3}$ Similarly, incidence rate of breast cancer has been increasing in Manipur and it is the commonest cancer in females in this region. ${ }^{4}$

Moreover, pathological parameters such as tumour size, histological subtypes, grade, status of hormone receptors, her 2 neu expression and lymph node are useful as prognostic factors in the management of breast cancer. $5,6,7,8,9,10,11$

Since hormone receptor status is an important predictive and prognostic factor, determination of hormone receptor status in patients with breast cancer before starting treatment is now a standard practice. ${ }^{12}$ The hormone receptors (HR) best studied in breast cancer are estrogen receptor (ER) and progesterone receptor (PR). ${ }^{13}$ Survival and response to hormone therapy are most favourable among women with tumors positive for both ER and PR expression, intermediate for tumours discordant on receptor status and least favourable for tumors negative for both. ${ }^{14}$ In view of the existence of well established correlation between hormone receptor status with patient treatment response, survival, the threat breast cancer poses and unavailability of any published report on hormone receptors from this region, the present study had been conducted to evaluate hormone receptor status in relation to age, stage, primary tumour size, histology, grading and lymph node positivity to create a database of breast cancer patients in Manipur.

\section{Methods}

This study is a retrospective case series study on 180 cases of operable breast cancer who were registered at Regional Cancer Centre, Regional Institute of Medical Sciences (RIMS), Manipur State after histopathological confirmation during the period from September 2015 to August 2018 and case notes of those 180 patients were reviewed for clinical presentation like ages, tumour size and metastatic lymph nodes positivity, histopathology, grading, hormone receptor status, staging and menstrual status. The patients were staged according to the TNM staging system (AJCC $7^{\text {th }}$ Edition). 180 patients had undergone either modified radical mastectomy or breast conserving surgery followed by adjuvant chemotherapy and radiation. Cases without complete information and unknown hormone receptor status were excluded in the present study. An approval from the Institutional Ethics Committee for research involving human subjects was obtained before the study was conducted. Confidentiality of the patient's identity was maintained. The data were analyzed using SPSS 21 and descriptive statistics was used as type of statistical analysis test. Tumour tissue was subjected to routine processing and sections were stained with H\&E. The histopathological sections were diagnosed based on WHO classification and graded adopting Modified Blooms Richardson grading system.

The formalin fixed, paraffin embedded tissues were subjected to ER and PR expression study. Specimens had been processed by the Horse Radish Peroxidase method. Protein retrieval had been done by microwave technique. The following antibody clones had been used: 1 . Mouse anti-human ER alpha1D5, 2. Mouse antihuman PR clone PgR636.

Only nuclear staining pattern was considered positive for ER expression (ER+) and $P R$ expression $(\mathrm{PR}+)$. A positive staining was defined when at least $1 \%$ of the tumour cells take up the nuclear stain of any intensity. Breast ductal epithelial cells acted as internal controls. ER, PR staining was quantified by using Allred score. All the slides were quantified by combining proportional score based on the percentage of cells showing nuclear stain and intensity score based on intensity of staining.

\section{The Proportional Score (PS) is as follows:}

$0=$ No staining

$1=<1 \%$ of cells showing nuclear stain

$2=1 \%-10 \%$ cells showing nuclear stain

$3=11 \%-33 \%$ cells showing nuclear stain

$4=34 \%-66 \%$ cells showing nuclear stain

$5=67 \%-100 \%$ cells showing nuclear stain 
Intensity score (IS) is as follows:

$0=$ No staining

1 = Weak staining

2 = Intermediate staining

3 = Strong staining

Total Score (TS): sum of proportional score + intensity score.

Scores of 0 and 2 were considered negative and scores of 3 to 8 were considered positive.

\section{Results}

As shown in Table-1, among 180 patients, 100 patients $(55.6 \%)$ were illiterate and only 18 $(10.0 \%)$ patients were from higher socioeconomic status (Class-I and II). 50.0\%, 30.0\%, and $10.0 \%$ of the total 180 patients were found to be in poor socio-economic classes-III, IV and V respectively. Among the patients, the ages ranged from 28 to 76 yrs. The mean age of presentation was $52.6 \pm 0.82 \mathrm{yrs}$. The number of patients reaches a peak between 31 - 50 years $(59.4 \%)$, then begins to decline in the age group of 51-76 years $(32.2 \%)$ as shown in Table-1. 109 patients $(60.6 \%)$ were post menopausal patients.

Mean size of the breast tumour was $7.0 \mathrm{~cm}$ diameter, ranging from $1 \mathrm{~cm}$ to $14 \mathrm{~cm} .16 .1 \%$ of tumour size were $<2 \mathrm{~cm}, 46.7 \%$ were between $2-5$ $\mathrm{cm}$ and $37.2 \%$ were $>5 \mathrm{~cm}$. The histological classification revealed a predominance of invasive duct carcinomas $(96.1 \%)$ followed by lobular carcinomas $(2.8 \%)$ and medullary carcinomas $(1.1 \%)$. Majority of the cases $(84.5 \%)$ had gradeIII tumour followed by grade-II $(14.4 \%)$ and grade-I $(1.1 \%)$ respectively.

Only $17.8 \%$ of total patients presented in stage-I, $42.8 \%$ in stage-II and $39.4 \%$ in stage-III respectively. During surgery, 1 to 3 nodes (41.5\%), 4 to 10 nodes (33.5\%) and more than 10 nodes $(25.0 \%)$ of axillary lymph nodes were removed. Mean number of involved nodes was 5 (range: 1-27). 90 cases (50.0\%) were both ER/PR-, 66 cases $(36.7 \%)$ were both ER+/PR+, 14 cases $(7.8 \%)$ were ER+ and 10 other cases $(5.5 \%)$ were only PR+.
Table-1: Patient characteristics $(n=180)$

\begin{tabular}{|c|c|c|}
\hline Variables & Frequency & $\begin{array}{c}\text { Percentage } \\
(\%)\end{array}$ \\
\hline \multicolumn{3}{|c|}{ AGES (YEARS) } \\
\hline Less than 30 & 10 & 5.6 \\
\hline $31-50$ & 107 & 59.4 \\
\hline $51-70$ & 58 & 32.2 \\
\hline Above 70 & 5 & 2.8 \\
\hline \multicolumn{3}{|l|}{$\begin{array}{l}\text { SOCIO ECONOMIC } \\
\text { STATUS }\end{array}$} \\
\hline I & 7 & 3.9 \\
\hline II & 11 & 6.1 \\
\hline III & 90 & 50.0 \\
\hline IV & 54 & 30.0 \\
\hline $\mathrm{V}$ & 18 & 10.0 \\
\hline \multicolumn{3}{|l|}{ EDUCATION LEVEL } \\
\hline Illiterate & 100 & 55.6 \\
\hline Primary education & 18 & 10.0 \\
\hline Secondary education & 33 & 18.3 \\
\hline $\begin{array}{ll}\begin{array}{l}\text { Above } \\
\text { education }\end{array} & \text { secondary } \\
\end{array}$ & 29 & 16.1 \\
\hline \multicolumn{3}{|l|}{$\begin{array}{l}\text { MENSTRUAL } \\
\text { STATUS } \\
\end{array}$} \\
\hline Pre-menopausal & 71 & 39.4 \\
\hline Post-menopausal & 109 & 60.6 \\
\hline \multicolumn{3}{|l|}{ HISTOPATHOLOGY } \\
\hline IDC-NOS & 173 & 96.1 \\
\hline Medullary & 2 & 1.1 \\
\hline ILC & 5 & 2.8 \\
\hline Others & 0 & \\
\hline \multicolumn{3}{|c|}{ HISTOLOGICAL GRADE } \\
\hline I & 2 & 1.1 \\
\hline II & 26 & 14.4 \\
\hline III & 152 & 84.5 \\
\hline \multicolumn{3}{|c|}{ STAGING (TNM Staging-AJCC $7^{\text {th }}$ edition) } \\
\hline I & 32 & 17.8 \\
\hline II & 77 & 42.8 \\
\hline III & 71 & 39.4 \\
\hline IV & & \\
\hline
\end{tabular}


Table-II: Hormone receptor status in relation to age, tumour size, stage, histology, grading, lymph node positivity $(\mathrm{n}=180)$

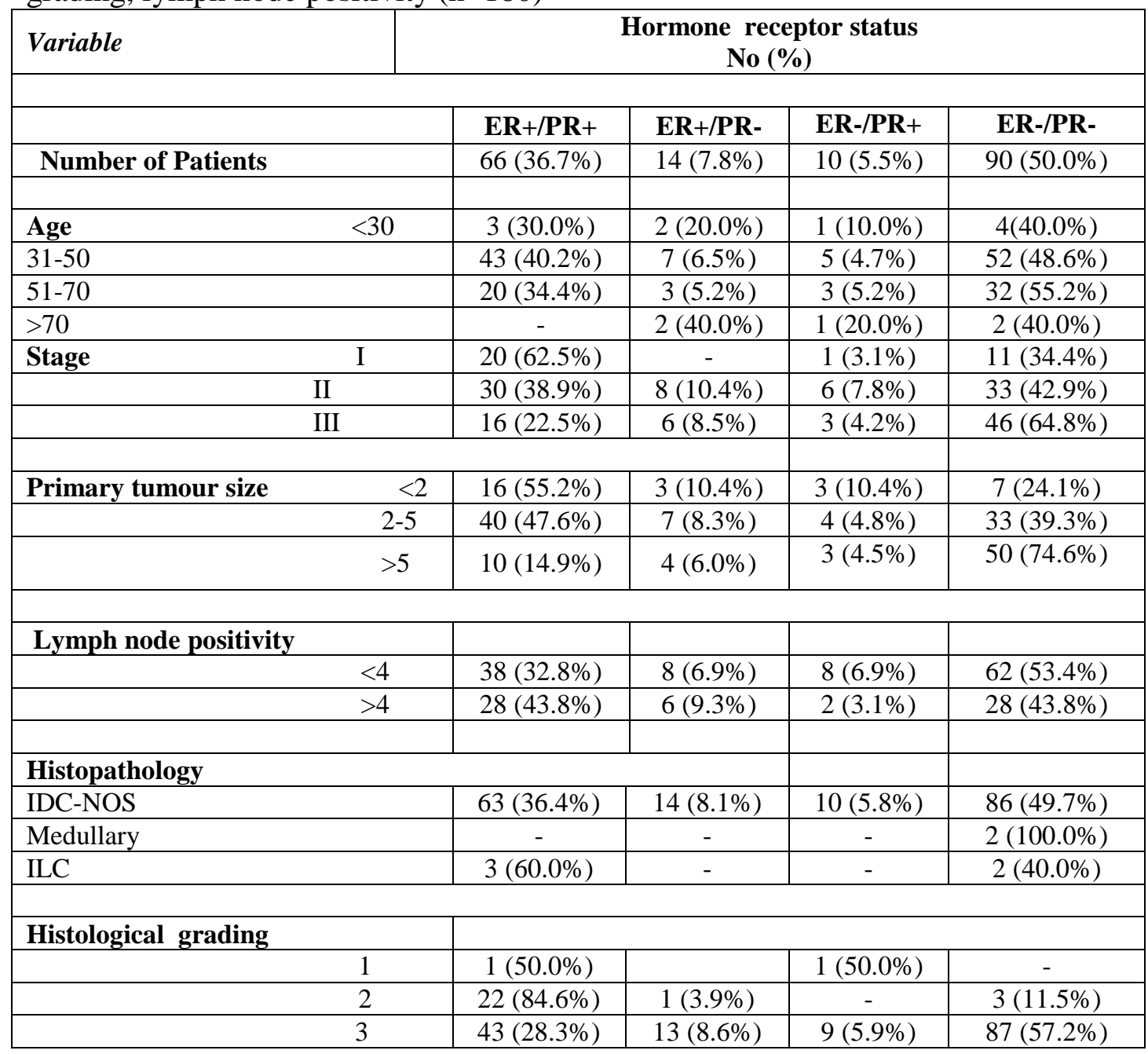

\section{Discussion}

Breast cancer is a biologically heterogeneous disease and has been one of the most heavily researched areas, not only in terms of its increasing incidence but also more and more understanding of its biological behaviour resulting in large evolving treatment paradigm. Suzuki $\mathrm{T}$ et $\mathrm{al}^{15}$ showed that ER+ breast cancers have a lower incidence of recurrence and a longer disease free interval regardless of tumour size or lymph node status. Thus, there is paramount importance of knowing ER/PR status of patients before starting any form of treatment.

In this present study, $55.6 \%$ patients were illiterate which is almost similar to other studies in India ${ }^{16,17}$ and only 18 patient $(10.0 \%)$ were from higher socio-economic status (Class-I and II). $50.0 \%, 30.0 \%$, and $10.0 \%$ of the total 180 patients were found to be in poor socio-economic classes-
III, IV, and V respectively. So in comparison to a study in Madhya Pradesh, more patients in our study were from very low socio-economic status family. ${ }^{17}$

In this study, majority of the patients (59.4\%) were in the age group of 31-50 years, similar to the findings of previous studies in other highincidence regions in southern india. ${ }^{18}$ In contrast to our findings, $37-42.0 \%$ of the patients belonged to the age group of 41-50 years in maximum studies of India. ${ }^{16,17,19,20}$ Moreover, in few other studies in India ${ }^{21,22,23} 48-54 \%$ of the patients were in the age group of 40-60 years. Out of total 180 patients, 90 patients $(59.4 \%)$ were in the age group of 31-50 years and ER-/PR- was found in 52 patients $(48.6 \%)$. It was observed that as the age increases, ER positivity of our patients does not increase in contrast to other Indian study. ${ }^{24}$ 
ER+ tumour in premenopausal and postmenopausal patients was found to be $39.4 \%$ and $47.7 \%$ respectively. Difference of ER positivity with respect to menopausal status in our study is not statistically significant $(\mathrm{P}$-value $=$ 0.275 ) similar to a study by Gautham Ranjan et al. ${ }^{25}$ But our study result is not in concordance with the study findings of an earlier study of Kaul $\mathrm{R}$ et $\mathrm{al}^{26}$ where the statistically significant difference in ER positivity was observed.

On further evaluation, increasing number of patients with ER negativity in respect to increasing stage was found in our study where ER negativity in stage 1 , Stage-II and Stage-III were $40.6 \%, 50.6 \%$ and $69.0 \%$ respectively.

Out of total 180 patients, most of the patients $(46.7 \%)$ had tumour size of $2-5 \mathrm{cms}$ and $\mathrm{ER}+\mathrm{PR}+$ was observed in $47.6 \%$ of them. In contrast to a study of Vedashree $\mathrm{MK}$ et $\mathrm{al}^{20}$, it was also observed that as the tumour size increases, ER/PR negativity increases where $24.1 \%, 39.3 \%$ and $74.6 \%$ of patients with ER/PR negativity had tumour sizes less than $2 \mathrm{~cm}, 2-5 \mathrm{~cm}$ and more than $5 \mathrm{~cm}$ respectively. In contrast to a study of Gulam Nabi Sofi et $\mathrm{al}^{27}$, increasing number of metastatic lymph nodes had decreasing ER/PR positivity in our study where ER/PR positivity were $43.8 \%$ and $32.8 \%$ in metastatic lymph node numbers less than 4 and more than 4 respectively.

Maximum numbers of grade-III tumour (57.3\%) were found to be ER-/PR- showing more aggressive tumour behaviour. ER positivity trend was highest for grade-II tumour (88.5\%) compared to grade-I (50.0\%) and grade-III tumours (36.9\%). Similarly PR positivity was more with grade-II $(84.6 \%)$ compared to grade-I tumour $(50.0 \%)$ and grade-III tumours (34.8\%). Our findings are comparable to the study findings of Malaysian patients. ${ }^{28}$ In contrast to our findings, majority of cases were grade-II (59.0\%) and maximum tumours in grade-I were $\mathrm{ER}+(59.0 \%)$ and $\mathrm{PR}+(37.0 \%)$ compared to grade-III and grade-II in a study from Nepal. ${ }^{29}$ Invasive ductal carcinoma was the most common histopathology accounting for (96.1\%) followed by invasive lobular carcinomas $(2.8 \%)$ and medullary carcinomas $(1.1 \%)$ respectively similar to other Indian studies. ${ }^{16,17,23,30,31}$ Similar to findings of Desai et $\mathrm{al}^{32}$, tumours of invasive duct carcinomas was predominantly ER-/PR-(49.7\%) in our study.

In the present study, more number of patients $(50.0 \%)$ were ER-/PR- and less number of patients $(36.7 \%)$ were $\mathrm{ER}+/ \mathrm{PR}+$ compared to the findings of few studies ${ }^{1,43}$ where percentage of ER-/PRranged from 30.7 to $42.19 \%$ and $\mathrm{ER}+/ \mathrm{PR}+$ patients ranged from $56.0 \%$ to $60.4 \%$. $44.4 \%$ of our patients were ER+ whereas $34.5 \%$ of patients in Himalayan region of northern India were $\mathrm{ER}+{ }^{26}$

Overall ER-/PR-(50.0\%) in our patients were comparable to the study findings of eastern Indian patients $^{34}$ but ER/PR negativity of Pakistani patients $(30.6 \%)$ and Caucasian $(21.8 \%)$ were less than our findings. ${ }^{35}$

In the present study, the overall ER+ was $44.4 \%$ and $\mathrm{PR}+$ was $42.2 \%$ which were more than the reports from Malaysia and study findings of Desai et al. ${ }^{32}$ But our findings were in contrast to the study findings from Indonesia ${ }^{36}$ where overall ER+ was $52.1 \%$ and PR+ was $48.5 \%$. In the present study, $42.2 \%$ of patients were $\mathrm{PR}+$ while $55.0 \%$ of the patients in the United States were PR. ${ }^{37}$ Our study showed PR positivity of $42.2 \%$ which was comparable with other studies from India which had shown PR positivity at $42 \% 39$ and $41.5 \%{ }^{25}$ but PR positivity in our study was more in comparison to few studies of Southern India $(33.3 \%)^{38}$ and Himalayan region $(36.4 \%){ }^{26}$

\section{Conclusion}

In this present study, majority of the patients were found to be illiterate and in poor socio-economic classes showing urgent need of awareness and screening programme in this region. It was observed that incidence rate of this cancer among younger age group has been increasing and as the age increases, ER positivity did not increase in contrast to other Indian study. Difference of ER positivity with respect to menopausal status was 
not significant. Maximum numbers of grade-III tumour were found to be ER-/PR-. On further evaluation, increasing number of patients with ER- in respect to increasing stage was found. It was also observed that as the tumour size increased, ER/PR negativity increased. More patients were ER-/PR- and less patients were $\mathrm{ER}+/ \mathrm{PR}+$. In view of the above findings, we feel that tumour biology of breast cancer in this particular region of India to be more aggressive compared with other Indian population. Further study on possible role of environmental, lifestyle, socio-demographic, ethnicity and genetic factors may be useful to further understand breast tumour biology of this region.

\section{References}

1. Globocan 2012. International Agency for Research on cancer, (IARC), section of cancer information.

2. Badwe RA, Gupta S. Breast cancer: An Indian perspective. Natl Med J India. 2011;24:193-7.

3. Ghoncheh M, Momenimovahed Z, Salehiniya H. Epidemiology, incidence and mortality of breast cancer in Asia. Asian Pac J Cancer Prev. 2016;17:47-52.

4. National Centre for Disease Informatics and Research, National Cancer Registry Programme, ICMR. Three Year Report of Population Based Registries, 2009-2011. Bangalore, India: NCDIR-NCRP (ICMR); 2014.

5. Fisher ER, Sass R, Fisher B, et al. Pathologic findings from the National Surgical Adjuvant Breast Project for breast cancer (Protocol No. 4): discrimination for tenth year treatment failure. Cancer 1984;53:712-23.

6. Carter CL, Allen C, Henson DE. Relation of tumor size, lymph node status and survival in 24,740 breast cancer cases. Cancer 1989;63:181-17.

7. Fletcher DM. Tumors of the breast. In: Diagnostic histopathology of tumors;
Elsevier, third edition, 2007:942.

8. Rosen PP, Harris JR, Hellman S, et al. Breast disease. Philadelphia JB Lippincott, 1987;181-5.

9. Bloom JHG, Richardson WW. Histologic grading and prognosis in Breast Cancer. $\mathrm{Br}$ J Cancer 1957;9:359-77.

10. Henson DE, Ries L, Freedman LS, et al. Relationship among outcome, stage of disease and histologic grade for 22,616 cases of breast cancer. Cancer 1991;68:21422149.

11. Elston CW, Ellis IO, et al. Pathological prognostic factors in breast cancer. The role of histological grade in breast cancer: experience from a large study with longterm followup. Histopathology 1991;19:403-10

12. Rastelli F, Crispino S. Factors predictive of response to hormone therapy in breast cancer. Tumori. 2008;94(3):370-83.

13. Mohamed FZ, Darwish H, Belal AM, Rajek WY. Some tumor markers and hormonal receptors as Prognostic Parameters of Breast Cancer. Indian J Res 2015;4(2):199-202.

14. Suvarchala SB, Nageswararao R. Carcinoma breast- histopathological and hormone receptors correlation. J Biosci Tech 2011;2(4):340-8.

15. Suzuki T, Miki Y, Nakamura Y, Moriya T, Ito $\mathrm{K}$, Ohuchi $\mathrm{N}$, et al. Sex steroid producing enzymes in human breast cancer. Endocr Relat Cancer 2005;12(4):701-20.

16. Rao M, Joshee R, Deval M, Sethi N. Clinico-morphological profile in breast cancer patients in a tertiary care hospital in western rajasthan. J Evolution Med Dent Sci. 2016; 5(4):262-5.

17. Shrivastava N, Gupta R, Gaharwar A P S. Clinco-pathological presentation of carcinoma of breast at tertiary care centre in vindhya region, rawa, Madhya Pradesh, india. Int Surg j. 2016; 3(3):1156-62. 
18. Mahapatra M, Satyanarayana S. Evalution of clinic: pathologic $\square$ ndings of breast carcinoma in a general hospital in southern india. Indian J Cancer. 2013; 50(4):297301.

19. Shoeb MFR, Pinate AR, Shingade PP. Risk factors and clinical presentations of breast cancer patients: a hospital based study. Int Surg J. 2017; 4(2):645-9.

20. Vedasree MK, Rajalakshmi V. Clinicopathological study of breast carcinoma with correlation to hormone receptor status \& HER2/neu. Indian $\mathrm{J}$ Pathol Oncol. 2016;3(4):690-5.

21. Agrawal KH, Rajderkar SS. Clinicoepidemiological pro $\square$ le of female breast cancers and its important correlates: a hospital based study. Natl J Community Med. 2012; 3(2):316-20.

22. Amgiasvasanth A.M, Patil PS. Pro $\square$ le of breast cancer patients attending a tertiary care centre: a cross-sectional study. Int J Community Med Public Health. 2016; 3(3):663-7.

23. Mench K, Phira T. A clinic-demographic study of patients with carcinoma of breast at tertiary health care centre. Int Med J. 2016; 3(10):884-8.

24. Taran R, Singla D, Kumbhaj P, Chitalkar PG, Gumdal V. Retrospective study of hormone receptor status in breast cancer patients in central India. Natl J Med Res. 2016;6(2):143-5.

25. Rajan G, Culas TB, Jayalakshmy PS. Estrogen and progesterone receptor status in breast cancer: a cross-sectional study of 450 women in Kerala, South India.World J Surg Oncol. 2014;12:120.

26. Kaul R, Sharma J, Minhas SS, Mardi K. Hormone receptor status of breast cancer in the Himalayan region of Northern India. Indian J Surg. 2011;73(1):9-12.

27. Sofi GN, Sofi JN, Nadeem R, Shiekh RY, Khan FA, Sofi AA et al. Estrogen receptor and progesterone receptor status in breast cancer in realtion to age, histological grade, size of lesion and lymph node involvement. Asian Pac J Cancer Prev. 2012;13(10):5047-52.

28. Kamil M, Khalid I, Hashim H, Biswas M, Kaur G, Islam R. Association of carcinoma breast: grade and estrogen progesterone receptor expression. JCPSP.2010; 20(4):250-2.

29. Pathak TB, Bashyal R, Pun CB, Shrestha S, Bastola S, Neupane S, et al. Estrogen and progesterone receptor expression in breast carcinoma. JPN. 2011;1(2):100-3.

30. Bogarapu CB, Vayalapalli MR, Bendi H, Mantra Sanjay. A retrospective study on the incidence of breast carcinoma in a tertiary care hospital. Int J Contemp Med Res. 2016; 3(6):1714-6.

31. Das N, Debbarma A, Saha A. Evaluation of clinico-pathological study of breast cancer in rural population. IOSR J Dental Med Sci. 2016; 15(9):67-9.

32. Desai SB, Moonim MT, Gill AK, Punia RS, Naresh KN, Chinoy RF. Hormone receptor status of breast cancer in India: a study of 798 tumours. Breast. 2000;9(5):267-70.

33. Eerola H, Aittomaki K, Seljavaara S, Nevanlinna H, Smitten K. Hereditary breast cancer and handling of patients at risk. Scand J Surg. 2002;91:280-7.

34. Chatterjee K, Bhaumik G, Chattopadhyay B. Estrogen receptor and progesterone receptor status of breast cancer patients of eastern India: A multi-institutional study. South Asian J Cancer. 2018;7(1):5-6.

35. Kakarala M, Rozek L, Cote M, Liyanage S, Brenner DE. Breast cancer histology and receptor status characterization in Asian Indian and Pakistani women in the U.S. - a SEER analysis. BMC Cancer. 2010;10:191.

36. Aryandono T, Harijadi, Soeripto. Hormone receptor status of operable breast cancers in Indonesia: correlation with other 
prognostic factors and survival. Asian Pac J Cancer Prev. 2006;7:321-4.

37. SEER*Stat database. [ http://seer.cancer.gov/statfacts/html/breas t.html]

38. Kuraparthy S, Reddy KM, Yadagiri LA, Yutla M, Venkata PB, Kadainti SVS, Reddy RPV. Epidemiology and patterns of care for invasive breast carcinoma at a community hospital in Southern India. World J Surg Oncol. 2007;5:56. doi: 10.1186/1477-7819-5-56.

39. Shet T, Agrawal A, Nadkarni M, Palkar M, Havaldar R, Parmar V, Badwe R, Chinoy RF. Hormone receptors over the last 8 years in a cancer referral center in India: what was and what is? Indian $\mathbf{J}$ Pathol Microbiol. 2009;52:171-174.

40. Kumar V, Tewari M, Singh U, Shukla HS. Significance of Her-2/neu protein over expression in Indian breast cancer patients. Indian J Surg. 2007;69:122-128. 